\title{
The temporal pattern of the contribution of fat to energy and of food groups to fat at various eating locations: implications for developing food-based dietary guidelines
}

\author{
NA O'Dwyer, SN McCarthy*, SJ Burke and MJ Gibney \\ Department of Clinical Medicine, Trinity Centre for Health Sciences, St. James's Hospital, James's Street, Dublin 8, \\ Republic of Ireland
}

Submitted 5 May 2004: Accepted 9 November 2004

\begin{abstract}
Objectives: To examine the temporal pattern of the number of eating occasions that occurred at home, at work and outside the home, and to examine the contribution of fat to energy and the contribution of 26 food groups to fat at home and outside the home.

Design and setting: Food intake data were collected using a 7-day food diary from a random sample of 18-64-year-old adults from the Republic of Ireland $(n=958)$. Respondents recorded the day, time and location of every eating occasion.

Results: The number of eating occasions was constant across the days of the week for meals consumed at home, whereas the number of eating occasions increased at weekends for meals outside the home. The contribution of fat to energy approximated the $35 \%$ recommendation at home from Monday to Friday, but increased above this on Saturday and Sunday. The contribution of fat to energy outside the home was always above the recommendation. The food groups that contributed most to fat were similar at home and outside the home. These included butter and full-fat spreads, fresh meat, meat products, meat dishes, biscuits, cakes and pastries, whole milk, and chips and processed potatoes.

Conclusion: The contribution of fat to energy was above the recommendations when eating outside the home, regardless of day of the week. A number of food groups have been identified that contributed most to fat intake outside the home and these might be targeted in developing public health nutrition strategies to reduce fat intake.
\end{abstract}

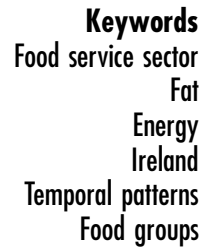

The need for the development of food-based dietary guidelines (FBDG) has been highlighted in recent years, in order to make nutritional goals more meaningful for the general population ${ }^{1}$. FBDG need to be culturally acceptable, practical and comprehensible for the target group. According to Kearney et $a l^{2}$, to ensure that FBDG are culturally acceptable it is important to consider where and when foods are eaten. This suggests a need to examine the temporal pattern of consumption across various locations.

An exhaustive literature search failed to find published papers examining nutrient intakes across day or hour in different locations. However, some papers ${ }^{3-13}$ were available that examined intakes across the days of the week without separating the data by location. These papers give conflicting results, with only some showing a significant effect of day of the week.

The North/South Ireland Food Consumption Survey (NSIFCS) established a detailed database of habitual food and drink consumption, including the day, time and eating location, for every item consumed ${ }^{14}$. This allows for the comparison of intakes across day or hour in different locations, which is the first such work to be carried out. The present paper aims to examine and compare the temporal pattern of the contribution of fat to energy and the contribution of 26 food groups to fat in the home and outside the home, which could be used in the development of future public health nutrition strategies.

\section{Methods}

Full details of the methods and sampling procedures used in the NSIFCS have been given by Kiely et $a l^{15}$ and Harrington et al. ${ }^{14}$. In brief, the NSIFCS was carried out in Ireland between 1997 and 1999 on a random representative sample of Irish adults. In total, 1379 adults aged 18 to 64 years, from both the Republic of Ireland and Northern Ireland, participated in the survey ${ }^{15}$. Data were collected on food intakes and a series of questionnaires was used to gather sociodemographic data ${ }^{14}$. In this study, only data from the Republic of Ireland were used $(n=958)$. 


\section{Food intakes}

Data on food and beverage intakes were collected using a 7-day food diary. Respondents recorded the day, time, eating location, meal type, quantity of food, cooking methods and recipes for each eating occasion. The foods were coded using McCance \& Widdowson's The Composition of Foods ${ }^{16}$ and published supplements ${ }^{17-25}$. Nutrient intakes were calculated using WISP ${ }^{\circledR}$ (Weighed Intake Software Package; Tinuviel Software, Warrington, $\mathrm{UK})^{14}$. The intake of fat as a percentage of energy was calculated excluding alcoholic and associated nonalcoholic beverages. Associated non-alcoholic beverages refer to non-alcoholic beverages consumed with alcoholic beverages, for example, in a gin and tonic. The contribution of fat to energy was compared with current recommendations ${ }^{26}$.

\section{Location of eating occasions}

Eight location codes were used for the eating locations when coding the food diaries for data entry. These were based on where the food was prepared rather than where the food was eaten. The eight locations were: (1) at home; (2) at work; (3) at a friend's home; (4) at a relative's home, family home or meals on wheels; (5) at a restaurant, hotel or pub; (6) at a coffee shop, shop, deli or sandwich bar; (7) at a takeaway or cinema; and (8) at social functions (parties, receptions). These eight codes were aggregated to form three groups in the same manner as in previous research in this group ${ }^{27}$. The abbreviated terms 'home', 'work' and 'outside the home' are used to describe the three new locations. 'Home' comprises food consumed at home, at a friend's home, at a relative's home, at a family home or from meals on wheels. 'Work' refers to food prepared and eaten at work only, for example food purchased in a work canteen. 'Outside the home' consists of food consumed in a restaurant, hotel, pub, coffee shop, shop, deli, sandwich bar, takeaway and cinema, and at social functions (parties, receptions). Given that the food service sector (FSS) is the primary focus of the present study, most of the analysis focused on foods consumed at home and outside the home.

\section{Number of eating occasions}

An eating occasion was defined as any meal, snack or beverage with greater than $0 \mathrm{~kJ}$. The mean number of eating occasions at each location was calculated for each day and for each hour for the consumers only at each location for the day or hour. A variable was created for hour that defined each hour by the 30 minutes before and the 29 minutes after the hour. Therefore, hour 10 refers to the time from 09.30 to 10.29 hours.

\section{Food groups}

The mean intake $(\mathrm{g})$ and the percentage of consumers were calculated for each of 26 food groups consumed at home and outside the home for day and for hour.
The percentage contributions of these 26 food groups to protein, fat and carbohydrate were examined by day for food consumed at home and outside the home. The data present the contribution of the food groups to fat only. Additional analysis of the food groups was also conducted, which included examining the intakes of the 26 food groups per MJ of food energy (excluding ethanol) at home and outside the home by day. The daily intake of each food group as a percentage of the weekly total at home and outside the home was also calculated to control for small numbers of consumers. The intakes per MJ of food energy (excluding ethanol) were examined to control for the differences in energy intakes between men and women and at the different locations.

\section{Statistical analysis}

Statistical analysis was carried out using SPSS ${ }^{\circledR}$ Version 10.0 for Windows ${ }^{\mathrm{TM}}$ (SPSS Inc., Chicago, IL, USA). Mean \pm standard deviation was calculated for the number of eating occasions, nutrient intakes and food group intakes by sex, eating location and day or hour. The method of calculating the latter was as follows. In calculating the mean by day, the sum of the variable per day was calculated per person for each location. The overall mean of these values was then examined. It was decided to calculate the sum of the variable per day for each respondent first, as the overall mean would then represent the average of the total number of eating occasions or the average of the total amount of a food group consumed on any given day. In contrast, when calculating the mean by hour, the mean of the variable per hour was calculated for each respondent for each location. The overall mean of these values was then calculated. The mean per hour was calculated per person first so that the overall mean would represent the average intake or average number of eating occasions at each hour and not the weekly intake or the weekly number of eating occasions at each hour.

A three-way analysis of variance (ANOVA) was conducted to examine the individual and interaction effects of sex, eating location and day of the week on the number of eating occasions and the percentage contribution of fat to energy. When significant effects existed, one-way ANOVA was used to examine the data for significant differences between groups. Homogeneity of variance was examined using Levene's test. In datasets with equality of variance, the Scheffe post hoc test was used to identify where these differences were. The Tamhane post hoc test was used where there was inequality of variance. Values of $P<0.05$ were considered statistically significant.

\section{Results}

Table 1 shows the mean number of eating occasions and the percentage of consumers at each location by day and 


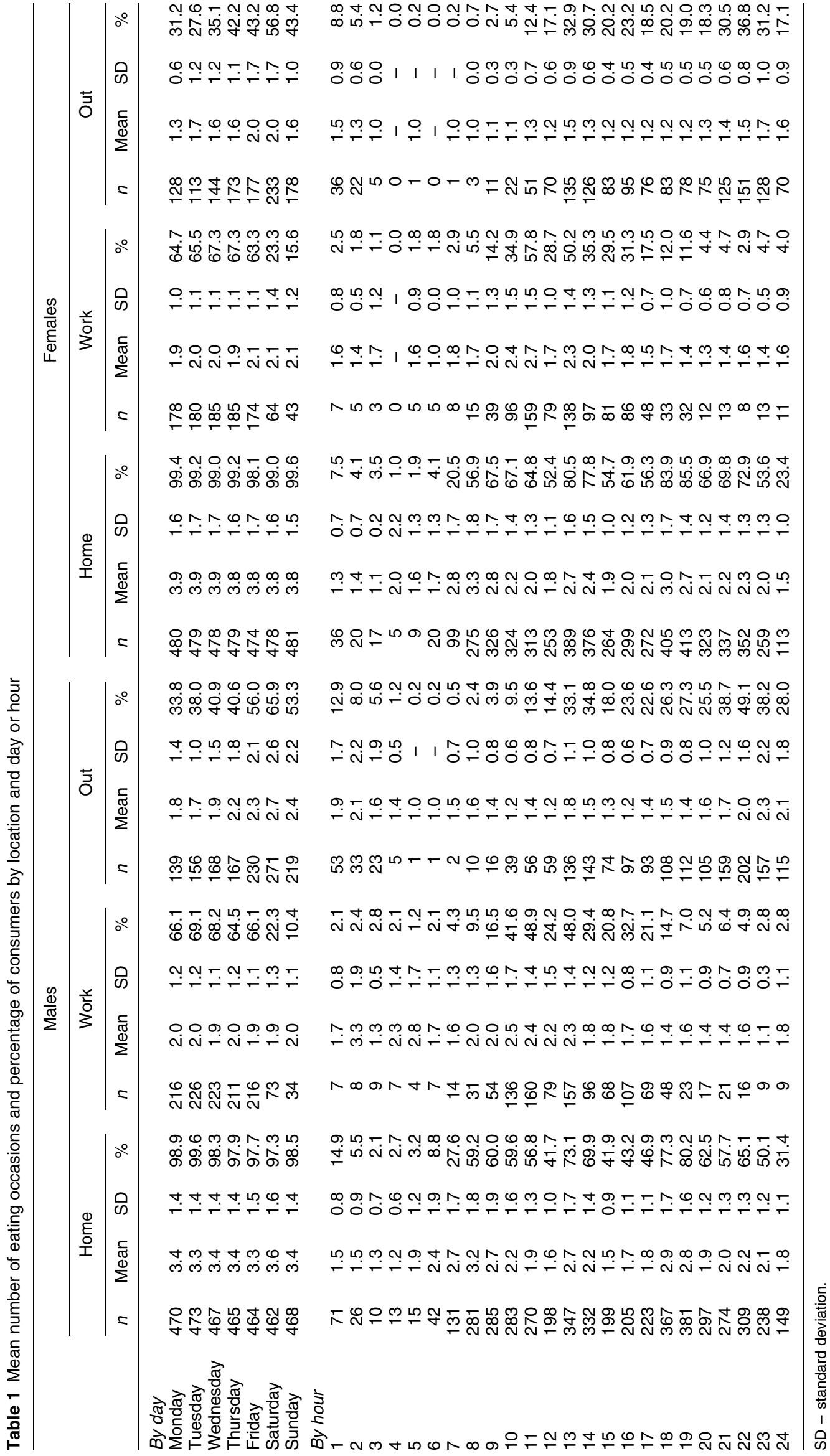


by hour for men and women separately. For foods consumed at home, the percentage of consumers and the number of eating occasions were constant across the days of the week. Three distinct mealtime peaks were evident for both, at hours 7-9, 13-14 and 18-20. For food consumed at work, the number of eating occasions was also constant across the days; however, the percentage of consumers fell at weekends. Across the hours of the day, two peaks were evident for the number of eating occasions and percentage of consumers at hours 10-11 and 13 at work. The number of eating occasions and the percentage of consumers increased at the weekend outside the home. Sex and location demonstrated a significant interaction effect $(P<0.001)$, which reflects the different patterns in the number of eating occasions in men and women across the locations. The three-way ANOVA also showed a significant interaction effect for location and day $(P<0.001)$. This reflects the changing pattern in the number of eating occasions across the week, in that the number of eating occasions decreased at work towards the weekend whereas, outside the home, the number of eating occasions increased.
Table 2 presents the mean percentage contribution of fat to food energy excluding the alcoholic and associated non-alcoholic beverages by day and hour. The contribution remained close to or slightly above the recommendation of $35 \%$ food energy from fat ${ }^{26}$ at home for men and women from Monday to Friday, but increased above this on Saturday and Sunday. Outside the home, the contribution of fat to food energy was always above the recommendation. Location and day had significant main effects $(P<0.001)$; however, the interactive effects did not reach statistical significance. A one-way ANOVA showed that for men, the contribution of fat at home was significantly greater $(P<0.01)$ on Saturday than on Monday to Friday; for women, the contribution of fat at home was significantly greater $(P<0.05)$ on Saturday than on Tuesday to Thursday. When eating out, no significant differences existed between the days of the week for either men or women. Across the hours of the day, the contribution of fat was above the recommendation at lunch and evening times. Outside the home, the contribution was above the recommendations for almost all hours.

Table 2 Mean percentage contribution of fat to food energy per day and hour for men and women by eating location, excluding alcohol and associated non-alcoholic beverages

\begin{tabular}{|c|c|c|c|c|c|c|c|c|c|c|c|c|}
\hline & \multicolumn{6}{|c|}{ Males } & \multicolumn{6}{|c|}{ Females } \\
\hline & \multicolumn{3}{|c|}{ Home } & \multicolumn{3}{|c|}{ Out } & \multicolumn{3}{|c|}{ Home } & \multicolumn{3}{|c|}{ Out } \\
\hline & $n$ & Mean & SD & $n$ & Mean & SD & $n$ & Mean & SD & $n$ & Mean & SD \\
\hline \multicolumn{13}{|l|}{ By day } \\
\hline Monday & 469 & 35.3 & 9.1 & 105 & 44.0 & 14.0 & 480 & 35.5 & 10.2 & 113 & 41.7 & 14.0 \\
\hline Tuesday & 473 & 34.7 & 10.1 & 121 & 45.3 & 11.9 & 479 & 34.7 & 10.3 & 104 & 42.5 & 14.1 \\
\hline Wednesday & 466 & 35.4 & 9.1 & 127 & 42.6 & 13.8 & 478 & 35.1 & 9.9 & 123 & 43.8 & 14.2 \\
\hline Thursday & 464 & 35.1 & 9.0 & 120 & 43.4 & 14.1 & 478 & 35.2 & 10.5 & 154 & 43.1 & 13.8 \\
\hline Friday & 463 & 35.7 & 10.3 & 184 & 43.7 & 12.5 & 472 & 35.9 & 10.3 & 158 & 45.6 & 12.1 \\
\hline Saturday & 462 & 38.2 & 10.6 & 189 & 43.4 & 12.6 & 477 & 37.5 & 10.2 & 193 & 45.8 & 11.4 \\
\hline Sunday & 468 & 36.6 & 10.1 & 159 & 44.6 & 12.7 & 481 & 36.4 & 9.9 & 147 & 46.0 & 15.1 \\
\hline \multicolumn{13}{|l|}{ By hour } \\
\hline 1 & 65 & 36.2 & 16.0 & 17 & 49.6 & 8.8 & 28 & 38.8 & 15.3 & 13 & 47.9 & 16.8 \\
\hline 2 & 23 & 32.3 & 17.5 & 8 & 48.4 & 11.2 & 18 & 39.7 & 15.4 & 11 & 35.9 & 16.9 \\
\hline 3 & 8 & 30.7 & 20.2 & 13 & 50.7 & 10.3 & 13 & 40.8 & 11.5 & 3 & 35.6 & 20.4 \\
\hline 4 & 10 & 36.3 & 16.0 & 3 & 50.0 & 5.2 & 5 & 32.9 & 23.7 & 0 & 0.0 & - \\
\hline 5 & 13 & 31.2 & 14.3 & 1 & 53.2 & - & 8 & 28.2 & 18.1 & 0 & 0.0 & - \\
\hline 6 & 41 & 26.0 & 13.7 & 1 & 19.7 & - & 20 & 27.8 & 14.0 & 0 & 0.0 & - \\
\hline 7 & 131 & 26.9 & 11.0 & 2 & 35.5 & 8.3 & 98 & 28.3 & 14.4 & 1 & 21.3 & - \\
\hline 8 & 279 & 28.4 & 12.3 & 8 & 43.9 & 9.6 & 275 & 27.2 & 12.8 & 3 & 48.6 & 7.9 \\
\hline 9 & 284 & 29.3 & 13.3 & 15 & 46.9 & 13.7 & 325 & 28.4 & 13.1 & 10 & 49.3 & 12.5 \\
\hline 10 & 281 & 32.6 & 14.5 & 36 & 45.8 & 14.8 & 324 & 30.3 & 13.8 & 22 & 48.8 & 12.2 \\
\hline 11 & 268 & 32.9 & 14.4 & 52 & 43.6 & 16.5 & 309 & 31.6 & 14.3 & 48 & 37.5 & 17.7 \\
\hline 12 & 196 & 34.7 & 14.0 & 47 & 40.8 & 15.8 & 251 & 33.0 & 14.7 & 70 & 44.0 & 13.7 \\
\hline 13 & 347 & 37.6 & 11.9 & 126 & 43.9 & 9.6 & 389 & 36.4 & 12.9 & 133 & 42.5 & 12.9 \\
\hline 14 & 332 & 35.5 & 11.4 & 131 & 40.8 & 12.6 & 376 & 37.2 & 12.5 & 124 & 42.5 & 13.6 \\
\hline 15 & 198 & 35.5 & 14.5 & 55 & 43.4 & 16.3 & 261 & 35.6 & 14.5 & 81 & 42.9 & 11.0 \\
\hline 16 & 202 & 34.2 & 15.1 & 68 & 41.3 & 16.2 & 296 & 34.7 & 14.9 & 92 & 43.6 & 13.1 \\
\hline 17 & 221 & 36.7 & 14.7 & 67 & 42.0 & 15.5 & 271 & 35.7 & 14.0 & 71 & 42.9 & 20.4 \\
\hline 18 & 366 & 37.4 & 11.2 & 70 & 41.6 & 15.3 & 402 & 37.3 & 10.7 & 70 & 43.0 & 14.2 \\
\hline 19 & 380 & 37.8 & 9.6 & 76 & 42.8 & 12.9 & 410 & 38.9 & 11.8 & 66 & 46.0 & 16.0 \\
\hline 20 & 291 & 37.6 & 13.1 & 53 & 46.5 & 13.0 & 322 & 37.7 & 13.8 & 55 & 43.5 & 12.8 \\
\hline 21 & 262 & 37.9 & 13.8 & 83 & 46.1 & 13.8 & 326 & 36.7 & 14.7 & 74 & 47.1 & 12.8 \\
\hline 22 & 291 & 36.6 & 13.3 & 68 & 44.6 & 15.5 & 339 & 37.6 & 15.4 & 64 & 43.4 & 19.1 \\
\hline 23 & 218 & 36.4 & 14.4 & 37 & 40.9 & 18.8 & 232 & 34.3 & 15.9 & 38 & 42.5 & 19.0 \\
\hline 24 & 132 & 36.3 & 14.3 & 41 & 46.2 & 7.8 & 101 & 35.8 & 16.2 & 19 & 47.3 & 13.0 \\
\hline
\end{tabular}

SD - standard deviation. 
Tables 3 and 4 present the mean percentage contribution of the 26 food groups to fat intake at home and outside the home for men and women, respectively. Details of the composition of the 26 food groups are presented in the Appendix. The tables present the data for each individual day of the week and the overall mean daily contribution of the food groups to fat. The food groups are ranked based on the mean daily column. Among men at home, butter and full-fat spreads, fresh meat, whole milk, meat products and biscuits, cakes and pastries were the five food groups which contributed most to fat. However, butter and full-fat spreads, fresh meat, biscuits, cakes and pastries, whole milk and meat dishes contributed most in women. Outside the home, the highest contribution to fat came from chips and processed potatoes, meat products, fresh meat, butter and full-fat spreads and creams, ice creams and desserts in men. In women, the same food groups contributed most to fat with the exception that biscuits, cakes and pastries replaced fresh meat.

Many differences were also evident across the days of the week (Tables 3 and 4). For men and women at home, the contributions of fresh meat, meat products, vegetables

Table 3 Mean percentage contribution of 26 food groups to fat intake for men at home and outside the home

\begin{tabular}{|c|c|c|c|c|c|c|c|c|}
\hline & Mean daily & Monday & Tuesday & Wednesday & Thursday & Friday & Saturday & Sunday \\
\hline Home & $n=475$ & $n=469$ & $n=473$ & $n=466$ & $n=464$ & $n=463$ & $n=462$ & $n=467$ \\
\hline Butter \& full-fat spreads & 15.2 & 16.2 & 15.1 & 16.6 & 17.4 & 16.6 & 15.5 & 14.7 \\
\hline Fresh meat & 13.5 & 12.6 & 13.5 & 11.4 & 11.8 & 9.1 & 12.9 & 18.8 \\
\hline Whole milk & 9.4 & 11.6 & 12.5 & 11.3 & 11.6 & 12.1 & 9.8 & 9.8 \\
\hline Meat products & 7.1 & 5.7 & 4.7 & 5.9 & 5.6 & 5.7 & 8.6 & 6.8 \\
\hline Biscuits, cakes \& pastries & 5.9 & 6.1 & 6.3 & 6.1 & 6.8 & 5.5 & 4.8 & 5.8 \\
\hline Chips \& processed potatoes & 5.5 & 4.2 & 3.9 & 4.5 & 4.7 & 5.9 & 5.1 & 4.6 \\
\hline Meat dishes & 5.4 & 5.3 & 7.6 & 6.2 & 4.5 & 4.6 & 4.3 & 3.1 \\
\hline Bread & 4.7 & 4.8 & 4.7 & 5.0 & 5.3 & 5.8 & 5.3 & 4.8 \\
\hline Cheese & 4.1 & 3.9 & 3.5 & 3.8 & 4.1 & 3.8 & 4.4 & 3.3 \\
\hline Vegetables \& vegetable dishes & 3.3 & 3.0 & 3.1 & 2.8 & 3.2 & 3.1 & 3.6 & 2.7 \\
\hline Eggs \& egg dishes & 3.2 & 3.0 & 2.7 & 2.5 & 1.9 & 3.3 & 4.1 & 3.0 \\
\hline Creams, ice creams \& desserts & 3.0 & 2.8 & 2.9 & 2.6 & 1.6 & 2.0 & 2.0 & 5.1 \\
\hline Fish \& fish dishes & 2.9 & 2.7 & 2.2 & 3.0 & 3.7 & 4.9 & 2.2 & 1.1 \\
\hline Low-fat spreads & 2.9 & 3.1 & 3.2 & 3.1 & 2.9 & 3.8 & 3.5 & 2.9 \\
\hline Soups, sauces \& miscellaneous foods & 2.2 & 1.7 & 2.3 & 2.3 & 2.4 & 2.1 & 1.8 & 2.1 \\
\hline Savouries & 2.1 & 2.6 & 1.5 & 1.6 & 1.7 & 1.6 & 2.4 & 1.5 \\
\hline Sugars \& confectionery & 2.0 & 2.2 & 1.5 & 2.3 & 2.0 & 2.1 & 1.8 & 2.2 \\
\hline Potatoes: boiled, mashed, baked & 1.9 & 1.9 & 1.9 & 2.1 & 2.2 & 1.6 & 1.3 & 2.2 \\
\hline Savoury snacks & 1.4 & 1.4 & 1.0 & 1.1 & 1.5 & 1.2 & 1.4 & 1.3 \\
\hline Breakfast cereals & 1.4 & 2.0 & 1.9 & 2.0 & 2.0 & 2.0 & 1.2 & 1.1 \\
\hline Low-fat milk & 1.2 & 1.5 & 1.8 & 1.9 & 1.5 & 1.5 & 1.9 & 1.5 \\
\hline Fruit, juices \& nuts & 0.8 & 0.6 & 1.0 & 0.9 & 0.7 & 1.0 & 1.2 & 1.1 \\
\hline Yoghurts & 0.4 & 0.4 & 0.6 & 0.5 & 0.5 & 0.3 & 0.5 & 0.2 \\
\hline Rice \& pasta & 0.3 & 0.4 & 0.6 & 0.3 & 0.3 & 0.4 & 0.3 & 0.2 \\
\hline Beverages & 0.0 & 0.0 & 0.1 & 0.0 & 0.1 & 0.0 & 0.0 & 0.0 \\
\hline Alcoholic beverages & 0.0 & 0.0 & 0.0 & 0.0 & 0.0 & 0.0 & 0.0 & 0.0 \\
\hline Outside the home & $n=370$ & $n=103$ & $n=120$ & $n=125$ & $n=119$ & $n=183$ & $n=187$ & $n=158$ \\
\hline Chips \& processed potatoes & 17.4 & 14.6 & 10.7 & 12.7 & 15.4 & 15.4 & 16.2 & 18.6 \\
\hline Meat products & 11.3 & 13.9 & 10.3 & 11.5 & 9.9 & 12.9 & 12.8 & 10.8 \\
\hline Fresh meat & 9.4 & 9.6 & 10.5 & 10.7 & 10.4 & 9.2 & 10.4 & 12.2 \\
\hline Butter \& full-fat spreads & 7.9 & 7.8 & 10.3 & 9.4 & 8.9 & 8.0 & 6.7 & 7.0 \\
\hline Creams, ice creams \& desserts & 6.5 & 3.2 & 6.7 & 3.4 & 5.3 & 3.1 & 7.0 & 7.4 \\
\hline Meat dishes & 5.4 & 1.6 & 2.6 & 2.4 & 2.4 & 5.5 & 7.6 & 4.1 \\
\hline Sugars \& confectionery & 5.2 & 7.4 & 7.1 & 6.9 & 4.8 & 4.9 & 6.0 & 5.1 \\
\hline Soups, sauces \& miscellaneous foods & 4.8 & 6.4 & 6.2 & 5.2 & 5.4 & 3.5 & 4.1 & 4.5 \\
\hline Vegetables \& vegetable dishes & 3.7 & 5.2 & 3.2 & 4.4 & 4.6 & 3.7 & 2.6 & 2.7 \\
\hline Whole milk & 3.7 & 6.3 & 8.2 & 6.8 & 5.0 & 5.4 & 3.4 & 3.3 \\
\hline Biscuits, cakes \& pastries & 3.5 & 2.3 & 3.7 & 4.3 & 3.7 & 2.3 & 3.3 & 2.2 \\
\hline Fish \& fish dishes & 3.4 & 3.6 & 1.1 & 3.0 & 4.9 & 4.0 & 2.1 & 1.2 \\
\hline Savouries & 3.3 & 1.5 & 1.1 & 3.0 & 2.5 & 2.8 & 4.0 & 4.0 \\
\hline Savoury snacks & 3.1 & 2.4 & 3.7 & 2.5 & 2.9 & 4.7 & 2.9 & 5.8 \\
\hline Bread & 2.9 & 2.7 & 5.4 & 3.5 & 4.1 & 3.4 & 2.1 & 2.4 \\
\hline Cheese & 2.2 & 2.3 & 2.4 & 3.4 & 1.9 & 3.1 & 1.5 & 1.0 \\
\hline Eggs \& egg dishes & 2.0 & 2.0 & 3.3 & 1.8 & 2.2 & 1.9 & 1.5 & 2.1 \\
\hline Fruit, juices \& nuts & 2.0 & 2.4 & 1.2 & 3.4 & 2.7 & 3.0 & 4.0 & 3.0 \\
\hline Potatoes: boiled, mashed, baked & 1.6 & 4.5 & 1.7 & 1.1 & 2.1 & 2.6 & 0.7 & 1.8 \\
\hline Low-fat milk & 0.2 & 0.0 & 0.1 & 0.1 & 0.7 & 0.1 & 0.3 & 0.2 \\
\hline Rice \& pasta & 0.2 & 0.0 & 0.2 & 0.1 & 0.1 & 0.2 & 0.3 & 0.2 \\
\hline Low-fat spreads & 0.1 & 0.2 & 0.1 & 0.0 & 0.0 & 0.1 & 0.4 & 0.2 \\
\hline Alcoholic beverages & 0.1 & 0.0 & 0.0 & 0.3 & 0.0 & 0.0 & 0.0 & 0.1 \\
\hline Beverages & 0.0 & 0.0 & 0.0 & 0.0 & 0.0 & 0.0 & 0.0 & 0.0 \\
\hline Breakfast cereals & 0.0 & 0.0 & 0.0 & 0.0 & 0.0 & 0.0 & 0.0 & 0.0 \\
\hline Yoghurts & 0.0 & 0.0 & 0.0 & 0.0 & 0.0 & 0.0 & 0.0 & 0.0 \\
\hline
\end{tabular}


Table 4 Mean percentage contribution of 26 food groups to fat intake for women at home and outside the home

\begin{tabular}{|c|c|c|c|c|c|c|c|c|}
\hline & Mean daily & Monday & Tuesday & Wednesday & Thursday & Friday & Saturday & Sunday \\
\hline Home & $n=483$ & $n=480$ & $n=478$ & $n=478$ & $n=478$ & $n=472$ & $n=477$ & $n=481$ \\
\hline Butter \& full-fat spreads & 12.3 & 12.3 & 12.5 & 12.8 & 13.5 & 13.4 & 12.8 & 12.3 \\
\hline Fresh meat & 10.5 & 12.9 & 9.8 & 8.8 & 9.2 & 5.9 & 10.0 & 14.6 \\
\hline Biscuits, cakes \& pastries & 7.5 & 7.3 & 7.4 & 8.6 & 7.2 & 7.1 & 8.0 & 6.4 \\
\hline Whole milk & 7.5 & 9.1 & 9.4 & 8.8 & 8.6 & 9.6 & 8.3 & 7.7 \\
\hline Meat dishes & 5.8 & 5.4 & 7.9 & 6.6 & 6.7 & 4.8 & 5.3 & 2.1 \\
\hline Meat products & 5.8 & 4.6 & 3.9 & 5.3 & 4.7 & 4.5 & 7.0 & 5.5 \\
\hline Bread & 5.2 & 4.9 & 6.0 & 5.1 & 5.7 & 5.8 & 6.2 & 4.8 \\
\hline Chips \& processed potatoes & 5.1 & 4.1 & 3.3 & 3.9 & 4.5 & 5.4 & 3.5 & 5.9 \\
\hline Vegetables \& vegetable dishes & 4.9 & 4.5 & 4.5 & 4.2 & 4.3 & 4.7 & 4.3 & 4.9 \\
\hline Cheese & 4.4 & 4.5 & 3.7 & 3.9 & 3.7 & 5.2 & 4.2 & 3.2 \\
\hline Creams, ice creams \& desserts & 3.7 & 2.4 & 2.8 & 2.6 & 2.5 & 2.3 & 2.8 & 7.2 \\
\hline Low-fat spreads & 3.3 & 3.8 & 3.8 & 3.5 & 4.1 & 3.7 & 3.9 & 3.3 \\
\hline Sugars \& confectionery & 3.3 & 3.4 & 3.1 & 3.3 & 3.8 & 2.6 & 4.0 & 3.6 \\
\hline Fish \& fish dishes & 3.2 & 2.0 & 3.4 & 4.1 & 2.2 & 5.6 & 1.6 & 1.3 \\
\hline Soups, sauces \& miscellaneous foods & 3.2 & 2.9 & 3.5 & 2.9 & 3.0 & 2.8 & 2.8 & 3.3 \\
\hline Eggs \& egg dishes & 2.8 & 3.0 & 2.4 & 2.3 & 2.5 & 2.7 & 3.5 & 2.2 \\
\hline Savouries & 2.7 & 2.4 & 2.1 & 2.4 & 2.3 & 3.4 & 1.6 & 2.6 \\
\hline Low-fat milk & 2.0 & 2.7 & 2.8 & 2.7 & 2.5 & 2.9 & 2.8 & 2.6 \\
\hline Breakfast cereals & 1.8 & 2.5 & 2.3 & 2.4 & 2.4 & 2.1 & 2.3 & 1.5 \\
\hline Savoury snacks & 1.7 & 1.3 & 1.5 & 1.6 & 1.9 & 2.3 & 2.0 & 1.2 \\
\hline Potatoes: boiled, mashed, baked & 1.3 & 1.6 & 1.5 & 1.5 & 1.2 & 0.8 & 0.6 & 1.8 \\
\hline Fruit, juices \& nuts & 1.0 & 1.1 & 1.2 & 1.3 & 1.9 & 1.0 & 1.1 & 1.0 \\
\hline Yoghurts & 0.5 & 0.7 & 0.5 & 0.6 & 0.7 & 0.7 & 0.5 & 0.3 \\
\hline Rice \& pasta & 0.3 & 0.4 & 0.5 & 0.4 & 0.6 & 0.4 & 0.3 & 0.2 \\
\hline Alcoholic beverages & 0.1 & 0.0 & 0.0 & 0.0 & 0.0 & 0.0 & 0.3 & 0.2 \\
\hline Beverages & 0.1 & 0.1 & 0.0 & 0.0 & 0.1 & 0.0 & 0.1 & 0.1 \\
\hline Outside the home & $n=389$ & $n=111$ & $n=103$ & $n=121$ & $n=152$ & $n=158$ & $n=193$ & $n=145$ \\
\hline Chips \& processed potatoes & 12.3 & 8.4 & 10.9 & 9.8 & 11.3 & 10.5 & 12.1 & 15.0 \\
\hline Butter \& full-fat spreads & 7.2 & 11.5 & 7.6 & 8.6 & 9.0 & 6.8 & 7.2 & 4.3 \\
\hline Biscuits, cakes \& pastries & 7.1 & 8.0 & 8.5 & 3.3 & 7.0 & 6.3 & 6.6 & 6.7 \\
\hline Meat products & 7.0 & 6.8 & 6.9 & 7.3 & 5.3 & 6.1 & 9.7 & 4.2 \\
\hline Creams, ice creams \& desserts & 6.8 & 3.4 & 4.2 & 5.7 & 5.3 & 7.4 & 6.9 & 7.8 \\
\hline Soups, sauces \& miscellaneous foods & 6.3 & 4.1 & 8.3 & 7.3 & 6.6 & 6.8 & 5.3 & 4.3 \\
\hline Whole milk & 5.5 & 12.5 & 8.9 & 8.0 & 9.1 & 9.2 & 5.3 & 7.3 \\
\hline Fresh meat & 5.5 & 4.8 & 4.3 & 5.4 & 4.3 & 6.1 & 5.1 & 5.0 \\
\hline Meat dishes & 5.5 & 4.5 & 2.9 & 5.7 & 5.7 & 4.6 & 3.4 & 3.8 \\
\hline Sugars \& confectionery & 5.5 & 7.7 & 8.5 & 5.7 & 4.3 & 4.4 & 4.9 & 8.9 \\
\hline Savoury snacks & 5.0 & 2.9 & 4.6 & 4.6 & 3.5 & 4.3 & 5.0 & 9.5 \\
\hline Vegetables \& vegetable dishes & 4.6 & 3.8 & 3.9 & 3.6 & 4.9 & 4.8 & 6.0 & 3.6 \\
\hline Savouries & 4.1 & 3.5 & 2.9 & 4.4 & 3.9 & 4.0 & 3.9 & 2.7 \\
\hline Bread & 4.0 & 6.1 & 3.2 & 6.1 & 7.5 & 3.8 & 5.2 & 1.8 \\
\hline Fish \& fish dishes & 3.5 & 3.0 & 4.1 & 3.3 & 2.4 & 4.4 & 2.1 & 2.1 \\
\hline Cheese & 2.8 & 2.8 & 3.3 & 3.7 & 2.7 & 2.7 & 3.2 & 2.6 \\
\hline Fruit, juices \& nuts & 2.2 & 1.3 & 2.8 & 2.1 & 3.0 & 2.9 & 1.3 & 5.8 \\
\hline Eggs \& egg dishes & 2.2 & 2.4 & 2.5 & 1.8 & 2.6 & 1.7 & 1.7 & 1.7 \\
\hline Potatoes: boiled, mashed, baked & 1.2 & 0.7 & 0.6 & 0.7 & 0.7 & 1.0 & 2.0 & 1.2 \\
\hline Alcoholic beverages & 0.6 & 0.0 & 0.0 & 1.0 & 0.0 & 0.1 & 1.0 & 0.3 \\
\hline Low-fat milk & 0.3 & 0.2 & 0.5 & 1.2 & 0.2 & 0.3 & 1.3 & 0.9 \\
\hline Rice \& pasta & 0.3 & 0.4 & 0.3 & 0.3 & 0.3 & 0.2 & 0.1 & 0.1 \\
\hline Low-fat spreads & 0.3 & 0.8 & 0.3 & 0.1 & 0.0 & 0.3 & 0.6 & 0.3 \\
\hline Beverages & 0.1 & 0.1 & 0.0 & 0.1 & 0.1 & 1.3 & 0.2 & 0.0 \\
\hline Yoghurts & 0.1 & 0.2 & 0.1 & 0.2 & 0.2 & 0.1 & 0.0 & 0.0 \\
\hline Breakfast cereals & 0.0 & 0.0 & 0.0 & 0.0 & 0.1 & 0.0 & 0.0 & 0.0 \\
\hline
\end{tabular}

and vegetable dishes and creams, ice creams and desserts were highest on Saturday or Sunday. Outside the home, chips and processed potatoes, creams, ice creams and desserts, savoury snacks and fruits, juices and nuts contributed most to fat at the weekend (Saturday or Sunday).

\section{Discussion}

According to Kearney et $a l^{2}$, consideration of the cultural acceptability of FBDG requires analysis of where and when foods are eaten, and thus temporal analysis and the examination of foods consumed outside the home were identified as areas of importance in the formation of FBDG. The present study set out to examine the temporal distribution of food and nutrient intakes in the FSS and therefore examined these intakes over days of the week and hours of the day. This makes this study quite unique as none of the available literature has examined the temporal patterns of intakes in the FSS. However, some papers have examined nutrient intakes across the days of the week and these can be used to make broad comparisons. 
In a previous study of the $\mathrm{FSS}^{27}$, the need to consider the contribution of fat to food energy excluding alcoholic beverages was highlighted. Initially, this method was also used in the present study. The results showed that, outside the home, the percentage contribution of fat to energy was always above the recommendation (38-42\%) for both men and women on all days of the week. However, on Saturday for men, the percentage contribution dropped to $38 \%$, which was the lowest point in the week, giving the impression that on Saturdays, when eating outside the home, men had diets with the lowest contribution from fat. It appeared that this was confounded by the use of soft drinks as mixers, which would lower the contribution from fat. Therefore, it was decided to analyse this further by removing the associated non-alcoholic beverages, for example, the tonic in a gin and tonic. In the case of a gin and tonic, the gin represents 68\% of the energy and the tonic $32 \%$. Following this adjustment, the contribution from fat intake across the week increased to $42-45 \%$ in men and $42-46 \%$ in women and the decrease in the contribution among men on Saturdays was no longer evident. This again highlights the potential confounding effect not just of ethanol, but of all of the energy of alcoholic beverages and associated mixers.

Previous research in this group has shown that the percentage contribution from fat to energy in the FSS was higher than that in the home ${ }^{27}$. The present study involved considerable food group analyses in an attempt to identify the potential foods consumed outside the home that led to the higher contribution from fat. A number of confounding methodological issues was identified in this regard. The actual intake $(\mathrm{g})$ of each of 26 food groups was examined for men and women separately across the days of the week at each location. This analysis was generally unhelpful since people consume a greater amount of most food groups at home and so have higher intakes. Attempts to overcome this by adjusting for energy intake did not improve the analysis. The energy intake outside the home is approximately a quarter (28\% for men, $22 \%$ for women) that inside the home and thus adjustment for energy distorts the relative intakes at home and outside the home.

The third method of analysis was to look at the contribution of the 26 food groups to fat. Few significant differences existed between home and outside the home. It was decided to rank the foods based on their contribution to fat, so that those that contributed most could be identified as target foods in developing public health nutrition goals for fat reduction (Tables 3 and 4). On that basis, the key foods to be targeted to lower fat intake in the FSS are chips and processed potatoes, meat products, butter and full-fat spreads, and creams, ice creams and desserts for both men and women. Similar findings were reported in other studies. Loughridge et al. ${ }^{28}$ showed that meats and chips contributed $24 \%$ and $11 \%$, respectively, to fat intake outside the home. This study is rather dated and it is possible that eating patterns may have changed; however, as there is a paucity of research in this area, it is important to make comparisons with papers that are available. Le Francois et al. ${ }^{29}$ reported that meat and fish had the greatest contribution to fat at $27 \%$, followed by bread, biscuits and pastries (18\%), dairy products (14\%) and fats and oils (11\%).

Within the present study, the contribution of fat to energy across the days of the week was examined separately for men and women at home and outside the home using one-way ANOVA. This showed that while an effect of day of the week was evident at home, no such effect existed when eating outside the home. A number of other studies can be used to make broad comparisons. However, it is important to bear in mind the differences that exist between the studies. None of these other studies separates the data by location and the populations and data collection methodologies used vary. The present study has taken the analysis further by separating the data by location and showed that the significance of the day of the week effect was dependent on the location.

A number of other studies have examined the actual fat intakes rather than the contribution to energy. Gibson et $a l^{3}$ examined intakes among female university students and showed that a significant day of the week effect existed for total fat intake. Post et $a l^{4}{ }^{4}$ showed that fat intake was higher among schoolgirls and schoolboys (age 12-17 years) on a weekend day than on a school day. De Castro et $a l^{5}$ also showed that fat intakes were significantly greater on weekend days (Friday to Sunday) than on Monday to Thursday in his study of 315 American adults (age 18-75 years). In contrast to these studies, St Jeor et $a l^{6}{ }^{6}$ found that while intakes were highest on Friday, no significant main effect existed for day of the week. Nicklas et $a l^{7}$ also found that there was no significant difference between Sunday and weekdays for total fat intake among 10-year-old children.

Other studies examined the actual fat intake and also the contribution to energy, and again these provide conflicting results. In some studies, no significant day of the week effect existed for either actual fat intake or the contribution of fat to energy ${ }^{8,9}$. Beaton et al. ${ }^{10}$, in a study of sales and office staff, found that a significant day of the week effect existed for intake of fat among women only. However, no significant effect was evident for the contribution of fat to energy among men or women. Similarly, in a study of 329 Hawaiian men, McGee et al. ${ }^{11}$ found that significant differences existed between the days of the week for the actual intake of fat but not for the contribution of fat to energy. Conversely, Thomson et $a .^{12}$ showed that a significant day of the week effect existed for the contribution of fat to total and food energy but not for actual fat intakes among Scottish men. Jula et al. ${ }^{13}$ examined three different study groups, one group over 7 days, a second group over 4 days (Thursday to Sunday) and a third population sample over 5 days (Monday, 
Tuesday and Friday to Sunday). Among the group over 7 days, a significant day of the week effect existed for the contribution of fat to energy but not for absolute fat intakes. Significant effects of day of the week were found for the actual fat intakes and the contribution of fat to energy in the other two groups.

In the present study, the data were not analysed by age group, as this would have produced too many tables giving results beyond the scope of this paper. However, previous research by our group has shown that younger people (18-35 years) tend to eat out more often than their older counterparts ${ }^{30}$ and that the contribution of fat to food energy was lowest among the older respondents $(51-64 \text { years })^{27}$. This suggests that the results found in the present paper may apply more to those in the youngest age group.

Two main conclusions can be drawn from the present study, which elaborate on those found in a previous study on the FSS in this research group. First, the issue of alcohol in examining the contribution of fat to energy was further refined in the present study. This continues to highlight the need for careful consideration in deciding which energy value to use. Second, the contribution from fat was greater from foods consumed outside the home than at home on all days of the week. The foods that contribute most to fat at home and outside the home have been identified. This information can now be used in the development of public health nutrition guidelines for targeting a reduction in the contribution of fat to energy.

\section{Acknowledgements}

The project was funded by the Irish Government under the National Development Plan 2000-2006.

\section{References}

1 Eurodiet core report. Nutrition \& diet for healthy lifestyles in Europe: science \& policy implications. Public Health Nutrition 2001; 4(2A): 265-73.

2 Kearney JM, Hulshof KFAM, Gibney MJ. Eating patterns temporal distribution, converging and diverging foods, meals eaten inside and outside of the home - implications for developing FBDG. Public Health Nutrition 2002; 4(2B): 693-8.

3 Gibson R, Gibson I, Kitching J. A study of inter- and intrasubject variability in seven day weighed dietary intakes with particular emphasis on trace elements. Biological Trace Element Research 1985; 8: 79-91.

4 Post B, Kemper HC, Storm-Van Essen L. Longitudinal changes in nutritional habits of teenagers: differences in intake between schooldays and weekend days. British Journal of Nutrition 1987; 57: 161-76.

5 De Castro JM. Weekly rhythms of spontaneous nutrient intake and meal pattern of humans. Physiology $\&$ Behavior 1991; 50: 729-38.

6 St Jeor ST, Guthrie HA, Jones MB. Variability in nutrient intake in a 28-day period. Journal of the American Dietetic Association 1983; 83: 155-62.

7 Nicklas TA, Farris RP, Bao W, Webber LS, Berenson GS.
Differences in reported dietary intake of 10 year old children on weekdays compared to Sunday: The Bogalusa Heart Study. Nutrition Research 1997; 17: 31-40.

8 Maisey S, Loughridge J, Southon S, Fulcher R. Variation in food group and nutrient intake with day of the week in an elderly population. British Journal of Nutrition 1995; 73 : 359-73.

9 Harrington KE. The study of periodicity of eating and public bealth nutrition issues. PhD thesis, University of Dublin, 2002.

10 Beaton GH, Milner J, Corey P, McGuire V, Cousins M, Stewart E, et al. Sources of variance in 24-hour dietary recall data: implications for nutrition study design and interpretation. American Journal of Clinical Nutrition 1979; 32: 2546-59.

11 McGee D, Rhoads G, Hankin J, Yano K, Tillotson J. Withinperson variability of nutrient intake in a group of Hawaiian men of Japanese ancestry. American Journal of Clinical Nutrition 1982; 36: 657-63.

12 Thomson M, Elton RA, Fulton M, Brown S, Wood DA, Oliver MF. Individual variation in the dietary intake of a group of Scottish men. Journal of Human Nutrition and Dietetics 1988; 1: 47-57.

13 Jula A, Seppanen R, Alanen E. Influence of days of the week on reported food, macronutrient and alcohol intake among an adult population in south western Finland. European Journal of Clinical Nutrition 1999; 53: 808-12.

14 Harrington KE, Robson PJ, Kiely M, Livingstone MB, Lambe J, Gibney MJ. The North/South Ireland Food Consumption Survey: survey design and methodology. Public Health Nutrition 2001; 4(5A): 1037-42.

15 Kiely M, Flynn A, Harrington KE, Robson PJ, Cran G. Sampling description and procedures used to conduct the North/South Ireland Food Consumption Survey. Public Health Nutrition 2001; 4(5A): 1029-35.

16 Holland B, Welch AA, Unwin ID, Buss DH, Paul AA, Southgate DAT. McCance \& Widdowson's The Composition of Foods, 5th ed. London: HMSO, 1995.

17 Holland B, Unwin ID, Buss DH. Cereal and Cereal Products. Third Supplement to McCance $\mathcal{E}$ Widdowson's The Composition of Foods, 4th ed. London: HMSO, 1988.

18 Holland B, Unwin ID, Buss DH. Milk Products and Eggs. Fourth Supplement to McCance \& Widdowson's The Composition of Foods, 4th ed. London: HMSO, 1989.

19 Holland B, Unwin ID, Buss DH. Vegetables, Herbs and Spices. Fifth Supplement to McCance $\mathcal{E}$ Widdowson's The Composition of Foods, 4th ed. London: HMSO, 1991.

20 Holland B, Unwin ID, Buss DH. Fruits and Nuts. First Supplement to McCance \& Widdowson's The Composition of Foods, 5th ed. London: HMSO, 1992.

21 Holland B, Welch AA, Buss DH. Vegetable Dishes. Second Supplement to McCance \& Widdowson's The Composition of Foods, 5th ed. London: HMSO, 1992.

22 Holland B, Brown J, Buss DH. Fish and Fish Products. Third Supplement to McCance E Widdowson's The Composition of Foods, 5th ed. London: HMSO, 1993.

23 Chan W, Brown J, Buss DH. Miscellaneous Foods. Fourth Supplement to McCance E Widdowson's The Composition of Foods, 5th ed. London: HMSO, 1994.

24 Chan W, Brown J, Lee SJ, Buss DH. Meat, Poultry and Game. Fifth Supplement to McCance $\mathcal{E}$ Widdowson's The Composition of Foods, 5th ed. London: HMSO, 1995.

25 Chan W, Brown J, Church SM, Buss DH. Meat Products and Dishes. Sixth Supplement to McCance \& Widdowson's The Composition of Foods, 5th ed. London: HMSO, 1996. 
26 Department of Health. Dietary Reference Values for Food Energy and Nutrients for the United Kingdom. Report of the Panel on Dietary Reference Values of the Committee of Medical Aspects of Food Policy. London: HMSO, 1991.

27 O'Dwyer NA, Gibney MJ, Burke SJ, McCarthy SN. The influence of eating location on nutrient intakes in Irish adults: implications for food-based dietary guidelines. Public Health Nutrition 2005; 8(3): 262-9.

28 Loughridge JM, Walker AD, Sarsby H, Shepard R. Foods eaten outside the home: nutrient contribution to total diet. Journal of Human Nutrition and Dietetics 1989; 2: 361-9.

29 Le Francois P, Calamassi-Tran G, Hebel P, Renault C, Lebreton S, Volatier JL. Food and nutrient intake outside the home of 629 French people of fifteen years and over. European Journal of Clinical Nutrition 1996; 50: 826-31.

30 O'Dwyer NA, McCarthy SN, Burke SJ, Wallace AJ, Gibney MJ. Where are we eating? Analysis of the number of eating occasions at various locations, with emphasis on the food service sector. Proceedings of the Nutrition Society 2002; 61: 87A.

\section{Appendix - Detailed description of the 26 food groups used in this study}

\begin{tabular}{|c|c|}
\hline Food group & Foods contained within the food group \\
\hline Rice \& pasta & Rice \& pasta (plain), flour, grains \& starches \\
\hline Savouries & Pizza, mixed pasta dishes, quiche \\
\hline Bread & $\begin{array}{l}\text { White bread, wholemeal bread, white \& wholemeal rolls, soda bread, scones, } \\
\text { bagels, croissants, ethnic breads }\end{array}$ \\
\hline Breakfast cereals & Ready-to-eat breakfast cereals, porridge, Ready Brek \\
\hline Biscuits, cakes \& pastries & Biscuits, cakes, buns \& pastries \\
\hline Whole milk & Whole milk \\
\hline Low-fat milk & Low-fat, skimmed, fortified, processed milks \\
\hline Creams, ice creams \& desserts & Creams, ice creams, puddings, chilled desserts, rice puddings, custard \\
\hline Cheese & Cheese \\
\hline Yoghurts & Yoghurts \\
\hline Eggs \& egg dishes & Eggs, egg dishes \\
\hline Butter \& full-fat spreads & Butter \& full-fat spreads \\
\hline Low-fat spreads & Low-fat spreads \\
\hline Potatoes: boiled, mashed, baked & Boiled, mashed \& baked potatoes \\
\hline Chips \& processed potatoes & Chipped, fried \& roasted potatoes, processed potato products \\
\hline Vegetables \& vegetable dishes & All vegetables \& vegetable dishes \\
\hline Fruits, juices \& nuts & All fruits, fruit juices, nuts, seeds, herbs \& spices \\
\hline Fish \& fish products & Fish \& fish products \\
\hline Fresh meat & Bacon, ham, beef, veal, lamb, pork, chicken, turkey, game, pheasant, rabbit \\
\hline Meat dishes & Offal dishes, beef, veal, lamb, pork, bacon, poultry or game dishes \\
\hline Meat products & Burgers, sausages, meat pies, pastries, sausage rolls, puddings \\
\hline Alcoholic beverages & Alcoholic beverages \\
\hline Sugars \& confectionery & Sugars, syrup, preserves, sweeteners, confectionery \\
\hline Savoury snacks & Savoury snacks \\
\hline Soups, sauces \& miscellaneous foods & Soups, sauces \& miscellaneous foods \\
\hline Beverages & Tea, coffee, carbonated beverages, diet carbonated beverages, squashes \& cordials \\
\hline
\end{tabular}

